\title{
Intervention of Bionics Design in Ceramic Art Creation
}

\author{
Lijuan Zhang \\ College of Art and Design \\ Zhengzhou University of Light Industry \\ Zhengzhou, China
}

\begin{abstract}
Today's society change rapidly, the high-speed, fast modern lifestyle and enhancement of the competition sense makes people's mind in a tension state, people's appreciation requirements of art constantly updated and change. Thus began to pursue a more natural, original art works, desire to get more relaxed lifestyle, since then people tend to have a return to natural psychology while tasting life, bionics design was emerged in keeping with this trend of fashion.
\end{abstract}

Keywords - ceramic art creation; bionics design

\section{INTRODUCTION}

Nature is full of living "good design" examples, for designers, it is an inexhaustible "Design Database". Such as inanimate mountains and rivers, animate birds and animals, as well as colorful flowers and trees, in addition to rich shapes, the brilliant colors also give people visual enjoyment. The different strange shapes of these creatures afford much food for thought which makes people busy with fancies. Our appreciation aside, whether we can get some inspiration from these exquisite designs? The answer is yes.

\section{THE CONCEPT, ORIGIN AND DEVELOPMENT OF BIONICS DESIGN}

\section{A. Concept of Bionics Design}

Bionics design based on bionics, through the research of outstanding function, shape, structure, color and other characteristics of natural biological system, selectively uses these principles and design features in the design process.

\section{B. The Origin of Bionics Design}

People in the distant years seem can understand the essence of their own survival, development and progress from natural ecosystem. People from savagery era into human civilization developed on the basis of imitating and adapting the laws of nature. Therefore, our ancestors greatly emphasized the harmony between man and nature during the creation activities of art and design, also greatly emphasized the coordination and symbiosis between design work and natural ecology. Since ancient times, design and nature have always been closely associated with each other, the first step of the creative activities for the ancient people start from natural imitation: We can see that from vortex pattern, bird, fish pattern on original painted pottery from the early days, to glutton pattern, thunder pattern on bronze ware ; from lotus pattern on celadon, Phoenix - head pots, to armchairs and crescent tables of Mingstyle furniture ; from the "human made image" with human head and dragon body, human head and bird body which constructed by ancient primitive man ,to the practical utensils according to the various animal forms in real life, such as the cow-shaped lamp, pig, eagle-shaped pot. Both are selected by the ancestors from the most beautiful and most vivid from or part of the form from natural forms, through highly refinement and summarization, exaggerated images and simplified abstract, so that the shape and ornamentation achieve the perfect combination, and then to achieve the art realm which are similar from the shape to the spirit. This is no doubt the crystal from the perfect combination between our ancestors' wisdom and the natural forms.

Human's thinking of nature imitation happened for a long time, which no doubt contributed to the birth of bionics, bionics is a emerging interdisciplinary subject which developed between bioscience and science of technology, it imitates the theory of biological system to build a new technology system. Bionics like the "bridge" and "bond", connect the bioscience and science of technology. The bionics design is developed on the basis of bionics.

The famous German industrial designer Luigi · Colani is vigorously advocates and practitioner of bionics design theory, his design philosophic thinking which contains human responsibility and design concept called on the harmony and unity between human society and nature, all have profound epoch-making meaning. His distinctive bionics design principles and methods, strong styling ideas and great vitality of the design, succeeded in influencing the future designers.

\section{Rise and Development of Bionics Design on Ceramics}

With our ancient bionic ceramic, as early as the Neolithic Age, people make a lot of bionic ceramics, such as pig-shaped ceramic whistle; ceramic birds in Xi'an Banpo; eagle-shaped ceramic tripod in Shaanxi Huaxian Taiping Zhuang ; Ceramic pigs, sheep, fish in Zhejiang Hemudu; pig-shaped ceramic Gui in Shandong Dawenkou ; dog-shaped ceramic Gui in Shandong Sanlihe, these ceramic as art works, they show not only its rich performance, but the main thing is the understanding of the objective world which evoked by their charm and the existence base of thinking and emotion. 
However, the rise of real bionics design does not begin from these ancient bionic ceramics, ancient bionic ceramics in fact, in a sense, only simple imitation to some mascots or some of the things in their familiar surroundings, of course, actually, this is the initial bud of bionics design and later played a very good bedding role for bionics design.

From all kinds of ancient Chinese bionic ceramics to the later bionic lotus bowl, it is not difficult for us to find that bionics design is not a simple, rough shape, but in the development of continuous improvement. It is no longer just for the shape forming, more important is to combine the nature and life together closely in order to make people feel natural and beauty in life. The bionics design at this time is obviously more natural and mature than the previous stage.

From Mansheng pot to Gongchun pot in Ming Dynasty, all show people's yearning and appreciation for natural and simple artworks. Until the Qing Dynasty, more Yixing ceramics involved elements of bionics design. For example, the Dongling pot from Chen Mingyuan in Qing Dynasty, it uses melon as the pot body, uses melon pedicel as pot cover, melon stem as pot handle, melon leaves as pot mouth, look it from far away, it simply like a little melon on the table. His imitation of a melon image and its full and round features are so vivid, make people feel the beauty of taste and visual sense.

So in modern times, since today's society changes rapid, the high-speed, fast modern lifestyles and the enhancement of competition sense make people's art appreciation requirements constantly updated and changed. Thus people begin to pursue a more natural, original art works and desire to get more relaxed lifestyle modification, and natural bionics design is pushed into a climax.

Intervention of bionics design in ceramic art creation is a good expression, because the soil is the most simple and closest to the original creator material, moderate and tolerant. Soil, water, fire coupled with modern ceramist's primitive fetishism impulse, naturally achieve a number of rustic artworks, of course it achieves people's returning to nature mentality. For example, Hei Junying's series of plant ceramic works, each piece gives a new, natural feeling, because she can put herself in a fascinated world, abandon experience actively, try the natural and without thinking feelings. This is the pleasure brought by the intervention of bionic design in ceramic art creation.

Of course, there are some foreign bionic-related ceramic works, such as the Barbara Nanning from Netherlands who is the author of "Flowers" ,"Inclined flower" as well as Taiwan ceramist A Liang's "pot" all show their pursuit and longing to the nature

Therefore, only open the window of his own soul and into the natural entrance, recognize and take advantage of their structure and function from all kinds of different forms in nature, seize the typical part of natural morphology structure, conduct inductive exaggeration, extract romantic charm and fusion with the people's expression and natural charm in ceramic design, and deducted into a ceramic style full of artistic vitality. This is the true value of bionics design in ceramic creation.

\section{BIONICS DESIGN IN CERAMIC CREATION}

\section{A. Advantages of Bionics Design in Ceramic Creation}

Nature is a wonderful creator, it can make the designers found many raw materials which bring inspirations for design: such as small delicate designs on butterfly wings, dragonfly's slim and beautiful shadows, conch's helical structure, as large as elephants' heavy clumsy posture, valiant majestic lion, monkey monkey's smart look, etc., all of these will become the driving force for the designers' design creation and they will be the key to open designers' wisdom and inspiration.

Bionics design is during the long learning process from people to the nature, through the accumulation of experience, selection and improvement of its function, form, and thus to create more excellent artifacts. Especially in today's information age, people's requirements for design are different from the past, not only pay attention to good functional properties, but also the pursuit of fresh form, simple, and focus on getting back to basics and product personality. The application of bionics design in ceramic creation naturally is a good direction, because the ceramic itself produced through the baptism of fire and soil, so of course it has more rustic and natural feeling.

Famous German designer Luigi Colani said: "The foundation of design should come from the truth which presented from nature of life." However, a good media of course is indispensable.

\section{B. Bionics Design Features in Ceramic Creation}

In ceramic creation, bionics design change the natural biological prototype into unique design elements, using creative thinking combine with ingenious technology, and then complemented by modern design ideas, create the general beauty with clever, exaggerated technique and comfortable shape. The general beauty not only has the original beauty but also with natural morphology structure. It is mainly divided into representational form bionic and abstract form bionic:

1) Representational form bionics design : representational form through the eyes structure use the natural physiological reaction to honestly reflect the external images into the eye film which will stimulate the nerve, after that it will feel a exist form, and it is representational form. It can reproduce the shape of the things more realistically. Since the representational form has good interests, lovely nature, organic, affinity and naturalness, so people are generally willing to accept and it is used more in toys, handicrafts and daily necessities. Such as Feng Shu's insects series, insect itself as a species with a huge number, various types, small size, and has a social population characteristics which is the most similar to human's and this quite amazed us. Use different materials such like ceramic, stainless steel, copper, to deconstruct the insect, enlarge the size of individual dozens or even hundreds of times, with painted color on insect's body and body shape and materials to strengthen the identity of each insect seems very interesting.

2) Abstract Form Bionics Design: abstract form uses simple shape to reflect the unique characteristics of the nature things. When this form act on people, it will produce a 
"psychological" form, this "psychological" form required the accumulation of life experience, through association and imagination to create the shape into the mind, that is an illusory, not real shape. However, the shape formed through the association of subjective emotions generated, rich colors, which form a physiologically very different feel from the fun. Not simply mechanically apply the techniques, but in concise lines free and easy style structure was established, gives rise to the effect of natural and lively association.

For example, Nermin Kura from the United States created the "purple passion" and "commitment". He adopted more vivid images, such as flowers, fruits and seed shell as a metaphor of an inclusive space, feels like the beginning of life's driving force, the birth of life and the shape. The abstract appearance gives unlimited shocking, which is the inspiration of art.

In short, representational bionic remain in the surface of biological imitation, the content of ideological and artistic relatively low; abstract bionic focus on refining the intrinsic nature of the object, it is a special kind of mental processing activity belongs to a high-level thinking, creative activity, it focuses on revealing the concept connotation of the object.

\section{The Spirit Conveyed by Bionics Design in Ceramic Creations}

Imagine the ecstasy after a blind man regain his sight, he believes that everything turned out so wonderfully rich: From the vivid expression of the plant to the weak breathing of the end of the bees, from the frozen moment of ancient extinct life in shale to cell mass which is fantastic as kaleidoscope, from the vast sky with moving stars to the little light spots in the grass, from the almost neurotic building arrangement of pinecone to the gorgeous coat of shellfish, from the frightening holes of solemn Taihu stone to the fine feathers of bird ...... then try to capture these images (there are spider silklike connections between them), break the dimensions of time and space, and then rebuild a new world. At any time, in our eyes, everything has its novelty side, which is the spirit need to be conveyed by ceramic creation.

In order to make new exploration and creation in ceramic art creation, it is necessary according to their different life experiences feelings; different artistic attainments; different aesthetic point of view, select the themes which affect them first to apply artistic innovation, colorful life create a vast world for out artistic expression. All kinds of things from nature provide us with an inexhaustible supply of material, if we feel it with our heart then we must be moved by what we see, even the ordinary things also contain the value and charm of beauty.

\section{The Future Prospect OF Bionics Design IN CERAMIC CREATION}

Throughout all aspects of basic necessities, all products design toward to the rustic, simple, elegant and crisp direction, which is the trend of the times. Historically speaking, it is the art return to its original nature, and ceramic art is also expanding and reclamation new art form fields. Modern art porcelain gives ceramic art new vitality from a new starting point and it also based on ceramic art.

On the other hand, the magic nature shows the exquisite life forms and show and colorful colors to human beings, but at the same time, nature also explains the life philosophy silently - harmony and symbiosis. Bionics Design in Ceramic Creation from the past follow the natural realism to today and future's intentionally realism plus practical, it meets nature pursuit demands from people's spiritual life. Chinese modern ceramic now is in a good atmosphere of development, and bionics design conforms to the trend of the times, meet people's return to nature psychology while enjoying their lives, it is bound to go further.

\section{CONCLUSION}

Bionics design in ceramic creation as a meeting point between creative activity of ceramic creation by human and nature, designers use their observation, thinking and design capabilities, insight into the subtle changes in nature, begin to imitate nature's thousands of images and show them in their own ceramic works. From a true representation of nature to a variety of imagery performances rely on nature, from the outside form bionic to variant transplantation of internal structure, bionics design has a unique image and meaning in ceramic design, it not only allows both the human living environment and natural achieve a high degree of unity, but also can bring convenience to people's daily work and life. How to maintain these beautiful things? Bionics design gives the best explanation.

\section{REFERENCES}

[1] Song Boyin. Grand national treasure. Shanghai Culture Publishing Company, 1990 edition

[2] Song Boyin. Song Boyin talk about ceramics. Shanghai Ancient Books Publishing Company, 2003 edition

[3] He Zhaocong. Modern ceramic art. World Ceramics Society, 2003 edition

[4] Ni Haishu. Vision and bionics. Knowledge Publishing Company, 1985 edition

[5] Wang Shouzhi. World modern design history. China Youth Publishing Company, 2002 edition

[6] Guangzhou Art Museum.New Ceramic: Work collection of Chinese Contemporary Young Ceramist Invitation Exhibition. Jiangxi Fine Arts Publishing Company, 2005 edition. 